\title{
Effects of Serum Thyroid Stimulating Hormone Levels on Prognosis in Patients with Advanced Non-Small Cell Lung Cancer
}

\section{Degirmencioglu $\mathbf{S}^{*}$, Ugurlu E and Yaren A}

Department of Medical Sciences, Pamukkale University, Denizli, Agean, Turkey

*Corresponding author: Serkan Degirmencioglu, Fahri Goksin Oncology Centre, Pamukkale University Hospital, Denizli, Agean, 20100, Turkey, Tel: 905358333655; 902583740876; Fax: 902582966001; E-mail: drserkandeg@hotmail.com

Received date: June 28, 2016; Accepted date: July 15, 2016; Published date: July 18, 2016

Copyright: (c) 2016 Degirmencioglu S, et al. This is an open-access article distributed under the terms of the Creative Commons Attribution License, which permits unrestricted use, distribution, and reproduction in any medium, provided the original author and source are credited.

\begin{abstract}
New indicators and more effective treatments are required to monitor the disease in advanced non-small cell lung cancer (NSCLC) due to less favorable prognosis. The purpose of our study is to evaluate the effects of serum thyroid stimulating hormone (TSH) levels on prognosis and survival in NSCLC patients. Sixty seven patients (62 males and 5 females) and 20 healthy volunteers (16 males and 4 female) were included in the study. Demographic, laboratory data and serum TSH levels of these two groups were compared. Statistically significantly reduced serum TSH levels were detected in patient group versus control group $(p=0.000)$. In our study, median survival time of patients with reduced TSH value was 225 days, while median survival time of patients with normal TSH value was 385 days; and the statistically difference was significant $(p=0.03)$. These results indicate that TSH can be a physiological factor in both carcinogenesis and progression of the diseases.
\end{abstract}

Keywords: Lung cancer; Thyroid hormones; Prognosis; Survival

\section{Introduction}

Genetic, immunologic and biochemical indicators having predictive importance in prognosis and survival of NSCLC have been discussed as well as metastatic NSCLC phenomena loss due to cancerindependent causes in which recurrence was not developed for 5 years following myxedema which directed the attention to the relation between thyroid hormones [1].

Effects of thyroid hormones on cancer have been researched for many years. Most clinical and epidemiologic studies have shown that decreased thyroid hormone and increased thyroid stimulating hormone (TSH) levels reduce the growing rate of the tumor in metastatic cancers [2-4].

The interaction between the cancer and thyroid hormones has become definite when thyroid hormones appeared to affect the cell over transmembrane integrin receptors. Integrin $\alpha v \beta 3$ receptor is expressed mainly in cells undergoing rapid mitosis. Thus, integrin receptors regulate the proliferative effect of thyroid hormone on endothelium cells and tumors [5].

Thyroid hormone receptor $\beta$ (TR $\beta$ ), one of nuclear receptors of thyroid hormones, induces hypoxia inducing factor 1 (HIF-1) transcription over Phosphatidylinositol 3-Kinase pathway [6]. HIF-1 has a key role responsible for angiogenesis, invasion and metastases in rapidly growing tumor cells [7]. HIF-1 expression is a prognostic indicator for kidney, breast and prostate cancers [8].

The purpose of our study is to compare serum TSH levels in patients with advanced NSCLC to control group and to evaluate the effects of serum TSH levels on prognosis and survival in advanced NSCLC patients.

\section{Materials and Methods}

\section{Patient and control group}

In our study, with the approval of Pamukkale University, Faculty of Medicine Medical Ethics Committee, 67 patients who applied to Medical Oncology Department for the first time were included in evaluations. All patients were chemotherapy naive and they were pathologically diagnosed with NSCLC.

Patients with advanced stage (stage IIIB and stage IV) whose performance status were $0,1,2$ according to the World Health Organization (WHO) classification were included in the study. Participation to the study was voluntary-based. Patients whose performance was 3 or worse or who had cerebral metastasis or who were being suspected for cerebral metastasis, who were 80 years-old or older, who had early stage (I, II and IIIA) disease were excluded from the study although they signed the informed consent form.

Control group was established consisting of 20 healthy patients who were taking no medication with any known disease aged from 53 to 79 (average $63.1 \pm 6.3$ ). It was considered that individuals of the control group could be compared to patients group in terms of age and gender. Healthy control group consists of 16 male (80\%) and 4 female (20\%) patients.

Age and gender of patients and control group, tumor type, treatments and pre-treatment performances of patients were recorded. Individuals composing control and patient group were interviewed and well informed about the purpose and scope of the study, and individuals submitted their written informed consent forms.

\section{Biochemical analysis}

Blood samples of individuals from patient and control groups were taken at 08:00-09:00 on empty stomach following at least 8-12 hours fasting. The thyroid stimulating hormone (TSH) was studied on taken 
blood samples with Roche/Hitachi Cobas c Systems, e 601 Module Device.

\section{Statistical analysis}

Statistical analysis was carried out with SPSS-17.0, for windows packaged program. Results were evaluated within the $95 \%$ confidence interval. Providing $\mathrm{P}<0.05$, they were accepted as statistically significant. Chi-square and Mann Whitney-U tests were applied to make comparison of control group and patients characteristics. Spearman and Pearson correlation tests were performed for correlation analysis. Kaplan Meier method was adopted for overall survival and unprogressive survival times and time-survival curves. Logistic regression test was applied for the analysis of survival and factor effecting progression.

\section{Results}

In our study, 62 males (92.5\%) and 5 females (7.5\%), in total 67 patients diagnosed with advanced (IIIB and IV) NSCLC were included. The average age of the patients was $62.9 \pm 8.7$ years. $44(65.7 \%), 15$ $(22.4 \%)$ and $8(11.9 \%)$ of sixty seven patients had squamous cell carcinoma, adenocarcinoma and other histologic types respectively. Performance status of the patients was 0 in $28(41.8 \%), 1$ in 30 (44.8\%), 2 in $9(13.4 \%)$. In healthy control group, 16 males $(80 \%)$ and 4 females (20\%) were included. Average of ages was $63.1 \pm 6.3$ years. They had no additional diseases and well performance. None of the individuals had smoking history. The primary clinical and demographic characteristics of patient and control group are shown (Tables 1 and 2).

\begin{tabular}{|l|l|l|l|}
\hline Characteristics & $\begin{array}{l}\text { Patients group }(\mathbf{n}=67) \\
(\%)\end{array}$ & $\begin{array}{l}\text { Control group (n=20) } \\
(\%)\end{array}$ \\
\hline Age (year) & $62.9 \pm 8.7$ & $63.1 \pm 6.3$ \\
\hline \multicolumn{2}{|l|}{ Gender (female/male) } & $5(7.5) / 62(92.5)$ & $4(20) / 16(80)$ \\
\hline $\begin{array}{l}\text { Performance } \\
\text { status }\end{array}$ & $0-1$ & $58(86.6)$ & $20(100)$ \\
\hline $\begin{array}{l}\text { Any other diseases } \\
\text { (yes) }\end{array}$ & $24(35.8)$ & 0 \\
\hline Smoking (yes) & $54(80.6)$ & 0 \\
\hline
\end{tabular}

Table 1: Demographic and clinical characteristics of patient and control group.

\begin{tabular}{|l|l|l|l|}
\hline & Patient $(\mathbf{n}=67)$ & Control $(\mathbf{n}=\mathbf{2 0})$ & $p$ value \\
\hline Hemoglobin (gr/dl) & $12.8 \pm 1.7$ & $14.5 \pm 1.0$ & $0.000^{*}$ \\
\hline Albumin (gr/dl) & $4.1 \pm 0.4$ & $4.4 \pm 0.3$ & $0.014^{*}$ \\
\hline TSH ( $\boldsymbol{\mu l U / m l )}$ & $1.06 \pm 1.07$ & $1.69 \pm 0.99$ & $0.001^{*}$ \\
\hline AST (IU/L) & $22.03 \pm 17.9$ & $20.4 \pm 4.8$ & 0.057 \\
\hline ALT (IU/L) & $25.12 \pm 25.1$ & $21.8 \pm 7.6$ & 0.210 \\
\hline Creatinine (mg/dl) & $0.91 \pm 0.21$ & $0.86 \pm 0.13$ & 0.173 \\
\hline
\end{tabular}

Table 2: Laboratory values of patient and control group (average \pm SD).

${ }^{\star} \mathrm{p}<0.05$ was as significantly accepted. SD: standard deviation.
It was considered to have similar distribution of age and gender whilst grouping. Laboratory values that are haemoglobin, albumin and TSH levels were low in patient group and detected as statistically significant (respectively $\mathrm{p}=0.000, \mathrm{p}=0.014$ and $\mathrm{p}=0.001$ ) (Table 2 ).

TSH cut-off value was accepted as $0.27 \mu \mathrm{IU} / \mathrm{ml}$ in our study. Survival rate was worse in those having TSH values under $0.27 \mu \mathrm{IU} / \mathrm{ml}$ value. Median overall survival time of patients with decreased TSH value was 225 days while it was 385 days for normal patients and the difference was statistically significant $(\mathrm{p}=0.03)$ (Figure 1).
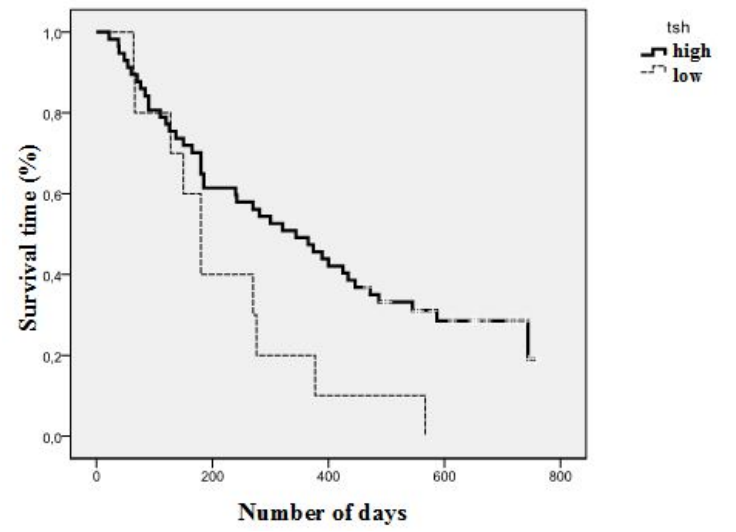

Figure 1: Overall survival curve according to TSH level.

When evaluated in multivariate analysis, decreased TSH (3.7 fold $\mathrm{p}=0.05$ ) was found to affect the overall survival in a negative way.

\section{Discussion}

Upon reporting metastatic NSCLC case that underwent spontaneous remission following myxedema coma, studies were concentrated on hypothesis suggesting that thyroid hormone secretion may increase carcinogenesis [1].

The hypothesis suggesting that thyroid hormones may also affect the risk of cancer progression as they have important role in physiological growth, maturation and metabolism, has been considered in several studies. However, it has not created a strong statistical effect with exception of the prospective studies carried out in Norwegian community. In this study, TSH counts were carried out in 9-yearfollow-up with a population of 30000 whose thyroid disease was not known at the beginning. In comparison with group having normal TSH value, in the group having TSH value under $0.5 \mathrm{mU} / \mathrm{L}$, risk of lung cancer increased 2.34 folds, and prostate cancer increased 1.97 folds (respectively HR 2.34; 95\% CI, 1.24-4.40 and, HR 1.97; 95\% CI, 1.04-3.76) [9]. In another study, risk of hyperthyroidism and breast cancer was reported to decrease [10].

The relation of breast cancer with thyroid hormones has been frequently studied. The major reasons of it are that estrogen-like effects of thyroid hormones play roles in breast tissue differentiation and development of breast cancer [11]. Additionally, breast and thyroid epithelial cells obtain iodine into cell with their common mechanism which is active transportation system [12].

In the study of Tosovic, as a result of monitoring healthy volunteers, statistically significant relation between increased level of triiodothyronine (T3) level and development risk of breast cancer was 
reported. However, no relation was found between serum TSH levels and breast cancer development [11]. In the study of Türken, thyroid hormones levels of 150 breast cancer patients and 100 healthy volunteers were evaluated and thyroxine (T4) levels were found statistically high in patient group [12]. Cristofanilli reported that possibility of breast cancer was $57 \%$ less in patients with primary hypothyroidism than in healthy individuals. Additionally, in event that breast cancer develops on hypothyroidism arm, these tumors have shown to be with in earlier stage and with lesser lymph nodes [10]. This situation suggests that decreased serum TSH level has negative effect on prognosis and survival for breast cancer.

In literature, no study has been conducted on the effect of hyperthyroidism on NSCLC prognosis and survival. However, case presentations were reported about hyperthyroidism developed due to primary lung cancer metastasis on thyroid tissue $[13,14]$.

In our study, we compared TSH levels of patient and control groups. We observed decreased values reaching at statistical significance for serum TSH levels $(\mathrm{p}=0.0001)$. In literature, no other study has evaluated serum TSH levels in patients with advanced NSCLC. Hercbergs et al. [15] compared 85 lung cancer patients and 85 healthy control groups without differentiating stages and types in his study. He reported that thyroid hormone supplemented primary hypothyroid patient groups' median survival was 3.4 months superior to euthyroid group (14.5 vs. 11.1 months, $\mathrm{p}=0.014)$ [15].

In our study, median overall survival time of patients with reduced TSH value was 225 days, while survival time of patients with normal TSH value was 385 days; and the statistically difference was significant $(\mathrm{p}=0.03)$. These results suggest that TSH can be a physiological factor in both NSCLC carcinogens and progression of the diseases.

Thyrosine kinase inhibitors are also known to cause hypothyroidism. Sunitinib used in the treatment of metastatic renal cell carcinoma was reported to cause hypothyroidism at rates reaching $71 \%$ [16]. In a recent study, progression free survival time of patients with developed sunitinib-associated hypothyroidism was observed to be statistically significantly higher than euthyroid group $(\mathrm{p}=0.07)$ [17].

Our study is the first study showing that hypothyroidism is a significantly positive prognostic factor in patients with advanced NSCLC. However, it should be supported with centralized attendant studies to be carried out with many more events.

\section{References}

1. Hercbergs A, Leith JT (1993) Spontaneous remission of metastatic lung cancer following myxedema coma: an apoptosis-related phenomenon? J Natl Cancer Inst 85: 1342-1343.
2. Shoemaker JP, Dagher RK (1977) Remissions of mammary adenocarcinoma in hypothyroid mice given 5-fluorouracil and chloroquine phosphate. J Natl Cancer Inst 62: 1575-1578.

3. Kumar MS, Chiang T, Deodhar SD (1979) Enhancing effect of thyroxine on tumor growth and metastasis in syngeneic mouse tumor systems. Cancer Res 39: 3515-3518.

4. Mishkin SY, Pollak R, Yalovsky MA, Morris HP, Mishkin S (1981) Inhibition of local and metastatic hepatoma growth and prolongation of survival after induction of hypothyroidism. Cancer Res 41: 3040-3045.

5. Cheng SY, Leonard LJ, Davis PJ (2010) Molecular aspects of thyroid hormone actions. Endocr Rev 31: 139-170.

6. Moeller LC, Dumitrescu AM, Refetoff S (2005) Cytosolic action of thyroid hormone leads to induction of hypoxia-inducible factor-1 $\alpha$ and glycolytic genes. Mol Endocrinol 19: 2955-2963.

7. Semenza GL (2009) Defining the role of hypoxia-inducible factor 1 in cancer biology and therapeutics. Oncogene 29: 625-634.

8. Kimbro KS, Simons JW (2006) Hypoxia-inducible factor-1 in human breast and prostate cancer. Endocrine-Related Cancer 13: 739-749.

9. Hellevik AI, Asvold BO, Bjoro T (2009) Thyroid Function and Cancer Risk: A Prospective Population Study. Cancer Epidemiol Biomarkers Prev 18: 570-574.

10. Cristofanilli M, Yamamura Y, Kau SW, Bevers T, Strom S, et al. (2005) Thyroid hormone and breast carcinoma. Primary hypothyroidism is associated with a reduced incidence of primary breast carcinoma. Cancer 103: 1122-1128.

11. Tosovic A, Bondeson AG, Bondeson L, Ericsson UB, Malm J, et al. (2010) Prospectively measured triiodothyronine levels are positively associated with breast cancer risk in postmenopausal women. Breast Cancer Res: 12: 33.

12. Türken O, Narin Y, Demirbas S, Onde ME, Sayan O, et al (2003) Breast cancer in association with thyroid disorders. Breast Cancer Res 5: 110-113.

13. Shirahama T, Ashitani J, Kodama T, Kyoraku Y, Sano A, et al. (2008) A case of lung cancer with hyperthyroidism. Nihon Kokyuki Gakkai Zasshi 46: 308-313.

14. Miyakawa M, Sato K, Hasegawa M, Nagai A, Sawada T, et al. (2001) Severe thyrotoxicosis induced by thyroid metastasis of lung adenocarcinoma: a case report and review of the literature. Thyroid 11: 883-888.

15. Hercbergs A, Mason J, Reddy C, Elson P (2004) Thyroid hormones and lung cancer: primary hypothyroidism is prognostically significant for survival in lung cancer [abstract \#4440]. 95th Annual Meeting, AACR; Orlando, Florida.

16. Illouz F, Laboureau-Soares S, Dubois S, Rohmer V, Rodien P (2009) Tyrosine kinase inhibitors and modifications of thyroid function tests: a review. Euro J Endocrinol 160: 331-336.

17. Sabatier R, Gravis G, Deville J, Bladou F, Walz J, et al. (2009) Hypothyroidism and survival during sunitinib therapy in metastatic renal cell cancer: a prospective observational analysis [abstract \# 317]. ASCO Genitourinary Cancers Symposium. 